\title{
Alfonso de Palencia y el humanismo italiano
}

\author{
Susanna ALLÉS TORRENT \\ Universitat de Barcelona $^{1}$ \\ susannalles@ub.edu
}

Recibido: $14 / 06 / 2012$

Aceptado: $15 / 09 / 2012$

\section{RESUMEN}

La relación del cronista Alfonso de Palencia con el humanismo italiano ha sido puesta de relieve en múltiples ocasiones. Su formación en Florencia y en Roma, sus inquietudes literarias en la línea de la recuperación de autores clásicos, en especial los historiadores de época romana, y sus contactos con personajes italianos son hechos reconocidos aunque no carentes de lagunas. El presente artículo pasa revista a algunos de los contactos bizantinos e italianos de Palencia, puntualiza algunos episodios y añade, además, otros nombres que habían pasado hasta el momento desapercibidos por la crítica, como el caso de Paolo Marsi, quien dedicó una composición en latín al humanista castellano. Además, se vuelve a replantear la propuesta de atribución palentina de un poema antimalatestiano dedicado al papa Piccolomini.

Palabras clave: Alfonso de Palencia, recepción humanismo italiano

\section{Alfonso de Palencia and the Italian Humanism}

\begin{abstract}
The relationship of the chronicler Alfonso de Palencia to the Italian Humanism has been emphasized several times. His academic training in Florence and Rome, his literary interest in the recovery of classical authors, particularly historians from the Roman period, and his contacts with some Italian humanists are well known although they are still lacking a more careful research. This paper deals with Palencia's Byzantines and Italian acquaintances, it clarifies some episodes of Palencia's life and points to some names that had so far gone unnoticed by the critics. This is the case of Paolo Marsi, who dedicated a Latin composition to the Castilian humanist. Furthermore, I will reconsider the hypothesis about Palencia's poem against S. Pandolfo Malatesta dedicated to the Pope Piccolomini.
\end{abstract}

Key words: Alfonso de Palencia, the reception of Italian Humanism

\footnotetext{
${ }^{1}$ Departament de Filologia Romànica. Facultat de Filologia. Universitat de Barcelona. Gran Via de Les Corts Catalanes, 585. 08007 Barcelona (España).
} 
SUMARIO: 1. Introducción. 2. Formación en Florencia y Roma. 3. El carácter humanístico de su producción literaria. 4. Bernardo Bembo y Paolo Marsi en Sevilla. 5. Alfonso de Palencia ¿autor de un poema antimalatestiano para Pío II? 6. Conclusiones. 7. Referencias bibliográficas.

\section{INTRODUCCIÓN}

Palencia vivió bajo los reinados de Juan II de Castilla y Enrique IV, y murió en el año 1492, a comienzos del reinado de los Reyes Católicos. Así pues, su época de formación y su actividad coincidieron con el periodo de recepción en España de las corrientes humanísticas procedentes de Italia, abarcando tanto su momento inicial como la primera fase de consolidación, una vez unificada la península.

De Palencia conocemos su formación en Italia, su interés por los autores clásicos, atestiguado especialmente por los textos que de ellos tradujo e incluso por la caligrafía de tipo humanista que adoptó, además de tener constancia, aunque lagunosa, de las relaciones personales que estrechó con exponentes destacados de la cultura italiana $^{2}$. Falta, sin embargo, una visión de conjunto que permita valorar el alcance del italianismo palentino y ahondar en las cuestiones aún pendientes de indagación crítica.

\section{FORMACIÓN EN FLORENCIA Y ROMA}

No es preciso recordar que la penetración del humanismo italiano en Castilla arranca en los tiempos del rey Juan II y prosigue bajo su hijo Enrique IV, una época en la que los contactos y los intercambios entre ambas penínsulas se intensificaron favoreciendo largas estancias de estudio y formación en Italia por parte de literatos castellanos, entre los cuales se contó Alfonso de Palencia.

Apenas cumplidos los 18 años, y seguramente con el patrocinio de Alfonso de Cartagena, Palencia realizó su primer viaje a Italia hacia finales de 1441 o principios de 1442, como él mismo recuerda en una carta a Jorge de Trebisonda ${ }^{3}$. Transcurrió sus primeros años en Florencia, ciudad adonde se había trasladado el Conci-

\footnotetext{
${ }^{2}$ Para la bibliografía básica sobre Alfonso de Palencia, véase Durán Barceló (1995), además de Allés Torrent (2008). Palencia demuestra haberse ejercitado en la lettera antica humanística, como demuestra la transcripción que hizo del Epitome Pompei Trogi Historiarum Philippicarum de Justino, ahora el Princeton University Library, Grenville Kane MS 42 Justinus, un manuscrito encuadernado en Florencia hacia 1450, según la nota del $\mathrm{f}$. de guarda, y varios autógrafos posteriores. Cf. Palencia (ed. 1998: XXXVI); Durán Barceló (1998: 311-318).

${ }^{3}$ «Verum quidem non inferior alacritatis compensatio fuit, quanto obtulit sese oportunitas visendi provinciam mihi ab adolescentia prima gratissimam, Italiam scilicet» (Palencia ed. 1982: 57), donde la expresión ab adolescentia prima nos sitúa en torno a los años cuarenta.
} 
lio de Ferrara desde marzo de 1439 y donde, por consiguiente, residían Basilio Bessarión, llegado a Italia en febrero del año anterior, y el mismo Jorge de Trebisonda, instalado en aquella ciudad desde el verano de 1440 como profesor de retórica del Studio fiorentino.

Aunque poco sabemos de esta estancia y de quiénes fueron exactamente sus interlocutores, lo cierto es que el ambiente florentino tuvo que ejercer un influjo intelectual sobre el joven. Lo más probable es que una vez llegado a Florencia viviera como doméstico en casa de Bessarión hasta la primavera de $1443^{4}$, fecha en que el bizantino marchó con el séquito del papa Eugenio IV hacia Roma. Es también probable que iniciara los estudios bajo la tutela de Jorge de Trebisonda desde su llegada o al menos entre 1442 y la primavera de 1443 (cf. Monfasani 1976: 43, 241; Della Torre 1902: 252).

Esta primera estancia florentina debió de prolongarse, pues, desde finales de 1441 hasta algún año después de la llegada del papa Nicolás V, es decir, entre 1447 y 1455. Ello viene avalado por la misiva de Donato Acciaiuoli, enviada a Palencia por encargo del librero Vespasiano da Bisticci el 24 de septiembre de 1463, donde recordaba los días que allí habían pasado juntos durante el pontificado de Parentucelli ${ }^{5}$.

Vespasiano da Bisticci, en efecto, fue otro de los personajes con los que Palencia estrechó relaciones en Florencia, aunque ignoramos cuándo se conocieron con exactitud. Lo que sí sabemos es que, a su regreso a España, siguió manteniendo correspondencia con él, ya que la Epístola IX demuestra que el librero le proporcionaba libros, copias manuscritas e informaciones sobre novedades ${ }^{6}$.

Algo después de esta fecha, hacia 1450, Palencia se hallaba, sin embargo, en Roma, donde volvió a coincidir con Trebisonda, que durante la primera parte del pontificado de Nicolás V había llegado a ser el lector más importante de los Studia

${ }^{4}$ En una epístola dirigida a Trebisonda y escrita durante su segundo viaje a Roma, Palencia recordará la benignidad y la ayuda recibida por parte del cardenal Bessarión durante una convalecencia y expresará el deseo de encontrarse de nuevo con sus dos maestros bizantinos: «Deum testor precipua mihi extitisse inter incitamenta denuo urbem hilariter visitandi, quod presentiam reverendissimi domini mei cardinalis Niceni desideratissimam possem intueri, quum fuerit mihi humanissimus ea tempestate dominus, quando mihi apud reverendissimam ipsius domini benignitatem impendenti domesticum (ut aiunt) famulatum, gravi postea valitudine diutius laboranti paternam opem elargiri dignatus est laudabili sapientia virtutumque amplo munimine etiam ornatissimus. Necnon visendi te non mediocris cupiditas mihi fuit» (Palencia ed. 1982: 61-62).

${ }^{5}$ Palencia explica en la epístola IX: «Renovarunt enim memoriam amicitie nostre, qua vivente $\mathrm{Ni}$ colao pontifice, ita inter nos devincti conjunctique fuimus, ut mihi persuasum sit nullum esse intervallum aut temporis aut loci, quod huic mutue benivolentie possit obesse. Distantia enim locorum, ut Aristoteles inquit [Eth.Nic., IX, 12], usum amicitie tollit, amicitiam non tollit» (Palencia ed. 1982: 71). Por lo que se refiere a la mención del Argirópulos, cf. Cammelli (1941: II, 71-72).

${ }^{6}$ Se trata de las actuales Epístolas IX y X (Palencia ed. 1982: 71-77); La IX, escrita por Palencia, es posiblemente autógrafa y fue descubierta años atrás en el Manuscrito 882 de la Abadía de Montserrat por Mundó (1964: 271-281). 
Humanitatis en el Studio Romano, lo cual dio una nueva oportunidad al joven alumno de seguir sus lecciones.

De la correspondencia conservada entre ambos y por las palabras del propio Palencia, se deducen las enseñanzas del bizantino: muy en especial cuando el humanista castellano se refiere a los malos y mentirosos oradores, capaces de defender la superioridad de una mosca sobre un águila, o cuando habla de Cicerón y la retórica (Palencia ed. 1982: 61). Asimismo, Palencia demuestra en sus cartas estar bien informado de la actividad intelectual de la ciudad de Florencia y de algunas traducciones que se están llevando a cabo ${ }^{7}$. Por lo demás, algunos testimonios manifiestan la gran variedad de nacionalidades, incluida la hispana, que convivían en las lecciones impartidas por Trebisonda y de las que debió de disfrutar el Nuestro: «Gregorius Trapezuntius» -recordaba Flavio Biondo- «publico Romae gymnasio Hispanos, Gallos, Germanosque multos, ut que nonnulli aliquando sunt magni praestantesque viri, simul cum Italicis oratoriae ac poeticae auditores habet» (Monfasani 1976: 80).

En aquella ciudad probablemente reanudaría también su relación con el Cardenal Bessarión, aunque por un período no muy prolongado pues este se transfirió a Bolonia entre 1450 y 1455 como legado pontificio. En cualquier caso, su presencia en Roma en los años cincuenta queda atestiguada, lo que amplía a una década su estancia en Italia $^{8}$.

Como nota curiosa y a propósito de la estancia en Florencia y en Roma, vale la pena recordar la especial predilección que sentía Palencia por la primera, a la que calificaba de «nobilissimae urbis Florentiae inter florentes orbis ciuitates florentissimae» (Palencia ed. 1998: II/2, 54). Este sentimiento de admiración aparece también en la carta dirigida a Jorge de Trebisonda desde Roma el 2 de enero de 1465; en ella afirma que los florentinos, además de ser los mejor instruidos, son superiores a los romanos, porque estos, acostumbrados a ver las pobres ruinas de lo que fue, viven anclados en el pasado, mientras que aquellos, al ver la grandeza actual de su ciudad, son «facundiores lepidioresque viros» (Palencia ed. 1982: 60). Así también en la carta dirigida a Vespasiano da Bisticci reitera el tópico de la decadencia de Roma, a la que tantos escritores se habían referido y que recogía la frase «Quanta Roma fuit, ipsa ruina docet»:

${ }^{7}$ Palencia se interesa por una nueva traducción de la Ética aristotélica, ya traducida en su momento por Leonardo Bruni, y quizás atribuible a Juan Argirópulos: «Libertas profecto florentina (cum bona venia dictum sit) nullam libertatem apud eos liberis detractoribus concedere debuisset, ut post diuturnam studentium disceptationem jam superanti Leonardo novum in media civitate, apud quam ipse floruit, calumniatorem objiceret Ethicos denuo transferentem, ne recens adolescentum favor patrum conscriptorum immortale decretum quantulumcumque iminuere posset》 (Palencia ed. 1982: 62-63)

${ }^{8}$ Para la documentación que testimonia su presencia en la ciudad de Roma, cf. Palencia (ed. 1998: XXXV, n. 3) y en Durán Barceló (1995: 312, D7). 
Nec me fugit, dulcis Vespasiane, ceteris in rebus animum meum perquam facile decipi posse, in extimatione vero qua metior nitidos Florentinorum mores certior sum nunquam erravisse. Quippe persuasi mihi, et recte, nullam in vestra urbe natura florenti asperitatem inmorari (Palencia ed. 1982: 75).

Palencia se encontraba todavía en la corte pontificia durante la toma de Constantinopla, acaecida el 29 de mayo de 1453, pues en sus Gesta Hispaniensia demuestra estar al corriente de la llegada de griegos en demanda de socorro papal contra los turcos, así como de la muerte de Álvaro de Luna, ocurrida el 2 de junio de $1453^{9}$.

Desde su regreso a la Península Ibérica, después, o tal vez a finales, de 1453, Palencia se dirigió con mucha probabilidad a Sevilla, ciudad que registraba hacia 14514.893 habitantes y en 1483-89 unos 6.896 como consecuencia de un notable desarrollo comercial que la había convertido en crisol de nacionalidades bajo el control ejercido por mercantes foráneos ${ }^{10}$. Sabemos que al poco tiempo se zambulló en los quehaceres políticos del Reino de Castilla como una figura de no poco relieve, y que sucedió a Juan de Mena como cronista y secretario de cartas latinas (6 diciembre de 1456), mientras trabajaba por la destitución de Enrique IV y en favor del infante Alfonso XII, tras cuya muerte defendió la causa de los futuros Reyes Católicos.

La ocasión de volver a Italia se presentó años después cuando, estando al servicio de Alfonso de Fonseca I, este le encargó efectuar un viaje en agosto de 1464. Inició así una segunda estancia en este país que duró aproximadamente un año (mayo de 1465 parece haber sido la fecha de su retorno a Castilla), y le permitió reanudar antiguas relaciones. Fue el caso del cardenal Bessarión, un encuentro que Palencia se auspiciaba para disfrutar de la «presentiam reverendissimi domini mei cardinalis Niceni desideratissimam» (Palencia ed. 1982: 61). Sabemos que Bessarión, finalizado su período boloñés en 1455, había iniciado una conspicua actividad diplomática, a través de Nápoles, Mantua, Nüremberg y Viena, hasta que en 1463 el papa Pio II, Enea Silvio Piccolomini, lo nombró Patriarca latino de Constantinopla. De nuevo en Roma, le había correspondido presidir el cónclave celebrado en agosto de 1464, del que había salido elegido el nuevo papa, Pablo II. Este fue el momento que vino a coincidir con el viaje de Palencia a Roma para solicitar ayuda contra el rey Enrique IV por cuenta de Alfonso de Fonseca I.

${ }^{9}$ La ejecución de Álvaro de Luna está descrita en Palencia (ed. 1998: II, 7, 27, p.71); mientras que el capítulo siguiente está dedicado a la llegada de la noticia de la toma de Constantinopla en la curia, donde Palencia parece haber estado presente (Palencia ed. 1998: II, 8, 7, p. 73).

${ }^{10}$ «Sevilla» -afirma Collantes de Terán- «debe su fortuna a la posición geográfica que ocupa, ello hace que en la Baja Edad Media sea uno de los destacados centros mercantiles del momento [...]. Pero este gran comercio es un tanto marginal a los sevillanos, en el sentido de que está en manos extranjeras o foráneas, genoveses, florentinos y burgaleses colonizan el comercio sevillano» (Collantes de Terán 1977: 424). (En la p. 163 el autor ofrece un cuadro sobre los «Vecinos de Sevilla por collaciones y barrios en el siglo XV y primer tercio del XVI que da una buena visión de conjunto). 
En verano del mismo año de 1464, Fonseca envió a Palencia a Roma para suplicar la intervención papal en el conflicto con el rey Enrique, de quien había pedido la deposición. Palencia explica todos los detalles de su viaje en Gesta Hispaniensia (Palencia ed. 1998: I, 7, 3); y en una carta a Jorge de Trebisonda, escrita en Roma el 2 de enero de 1465, manifestaba el pesimismo con que había emprendido el viaje sabiendo de antemano que la curia pontificia no escucharía su demanda (Palencia ed. 1982: 57).

El viaje tuvo lugar entre la muerte de Pío II, el 15 agosto, y la elección de su sucesor veneciano, Pablo II, el 30 de agosto de 1464, tal y como lo aclara el propio Palencia en Gesta Hispaniensia (Palencia ed. 1998: VII/3/4, 292). La presentación de su demanda tuvo lugar en septiembre de 1464 ante una audiencia de la que formaban parte el cardenal Bessarión y Guillaume d'Estouville. Palencia estaba acompañado por el procurador del marqués de Villena, Pedro Fernández de Solís, el procurador del conde de Plasencia, Antón de Paz, deán de Salamanca, y el procurador del arzobispo de Santiago, Diego Alfonso, mientras que como representante del bando enriqueño y como acusador de Fonseca asistía Suero de Solís (Palencia ed. 1998: VII/3/5, 293). Por aquella misma época, residían en Roma otros españoles que seguramente intervinieron de una u otra forma en el proceso, como los cardenales Juan de Mella, Juan de Carvajal, y Juan de Torquemada ${ }^{11}$. Según la versión de Palencia, el resultado fue que Enrique cedió ligeramente a las pretensiones de los nobles y se anularon las sentencias en contra de Fonseca I (en Portillo, 6.x.1464). Pero en su conjunto la embajada no tuvo el éxito esperado y el nuevo papa descartó la deposición de un rey ya coronado.

Sobre esta embajada, Tate (1993: 179) lamentaba la escasez de otros documentos aparte del testimonio de Palencia, y la situación no ha variado hasta hoy. Con todo, creo que una vía hasta ahora desconocida puede abrirse a partir de otras correspondencias. Así, en una carta al cardenal Bessarión, con fecha de 8 de mayo de 1465, Jacopo Ammannati informaba de las novedades que se habían producido en Roma y aludía probablemente a la embajada en cuestión:

Pontifex valet, fratres tui etiam valent. Cardinalis Sanctae Priscae ad titulum Sancti Laurentii in Damaso est translatus: aeger et vix animam trahens, duos potentes et gratiosos in petitione hac vicit. Auditi nudiustertius sunt oratores Hispani: oboedientiam pro more obtulerunt. Ea nullas condiciones petitionesve habuit, hortati tantum pontificem sunt ad continuam fidei causam. Praesul Legionensis, quem nosti, verba fecit (Ammannati 1997: II, 706).

${ }^{11}$ Para Torquemada, Palencia tiene buenas palabras «episcopus cardinalis Prenestinus, alias Sancti Sixti, uir religiosus ordinis Predicatorum honestissimus doctissimusque et sacrae theologie professor clarissimus» (Palencia ed. 1998: VII, 4, 9, p. 299); pero Mella y Carvajal son acusados de corrupción a lo largo de este capítulo (Palencia ed. 1998: VII, 4). 
El «cardinalis Sanctae Priscae» al que hace referencia Ammannati debe identificarse con Juan de Mella, quien ostentaba ese título desde el 17 de diciembre de $1456^{12}$. A la muerte del cardenal de San Lorenzo en Damaso, en Roma, Ludovico Scarampi Mezzarota, acaecida el 22 marzo de $1465^{13}$, el cargo pasó al ya viejo cardenal español, Juan de Mella, presente en algún momento, como he dicho, en la embajada. El editor de esta epístola, P. Cherubini, identifica también al «Praesul Legionensis» con el veneciano Giacomo Venier, nuncio papal en León desde enero de 1463, igualmente presente en el acto, y que, por lo que dice Ammannati, hizo las veces de portavoz ${ }^{14}$. Por lo que se refiere a los «oratores Hispani», Cherubini subrayaba que no tenía noticias de una visita de embajadores españoles por esa época (Ammannati 1997: II, 706), pero, a juzgar por los datos antes indicados concretamente el cambio de sede de Mella, los «oratores hispani» y al «preasul Legionensis», todos participantes en la embajada-, creo que Ammannati se estaba refiriendo a la misión realizada por Palencia. Emerge además otro dato: Bessarión debió de presidir la primera parte del proceso, iniciado en septiembre de 1464, como bien indica Palencia, pero no asistió a su desenlace, ya que no se encontraba en Roma, por lo cual recibe la epístola de su amigo Ammannati. Si mi hipótesis es correcta, ello significaría que el 6 de mayo de 1465 (correspondiente al «nudiustertius», 'anteayer' con respecto a la fecha de la carta) Palencia se hallaba aún en la ciudad para oír la resolución final del pontífice. Pocos días después Palencia debió de emprender el viaje de regreso, pues a mediados de junio lo encontramos de nuevo en Sevilla.

Esta fue probablemente la última vez que Palencia vio al bizantino, ya que en noviembre de 1464, Bessarión abandonó Roma, junto con Estouville y el español Juan de Carvajal, para ocuparse en calidad de comisarios de la cruzada contra los turcos. En cambio, como he dicho, nuestro autor permaneció en la ciudad cinco meses más, hasta mayo del año siguiente.

A su regreso reanudó la actividad política en defensa de Isabel de Castilla e intervino en las acciones diplomáticas desarrolladas para favorecer su matrimonio con Fernando de Aragón, lo cual lo llevaría a viajar y a reunirse con las más altas personalidades de la época. Con todo, como veremos, su residencia siguió siendo Sevilla, y no decreció su interés por la realidad europea y especialmente italiana. Así se trasluce de sus Gesta Hispaniensia, donde narra la conjura de los Pazzi sucedida en abril de

${ }^{12}$ Juan de Mella (†12 octubre 1467), nombrado obispo de Zamora el 4 de abril de 1440, pasó a ser titular de Santa Prisca el 17 de diciembre de 1456, y posteriormente obtuvo el título de San Lorenzo in Damaso marzo de 1465; cf. Eubel (1910-1914: II, 12 y 64).

${ }^{13}$ Ludovico Scarampi Mezzarota ( $† 22$ marzo 1465) fue patriarca de Aquileia (1 julio 1440) y después pasó a ser el titular de san Lorenzo en Damaso, cf. Eubel (1910-1914: II, 8 y 63).

${ }^{14} \mathrm{El}$ editor señala: «Nel margine di $\mathrm{Z}$, a stampa è scritto: "Legionensis, qui postea fuit Concensis et cardinalis": si tratta di Antonio Giacomo Venier, marchigiano» (Ammannati 1997: II, p. 706). 
$1478^{15}$-recuérdese que también Angelo Poliziano había narrado estos hechos hacia agosto de ese mismo año, tomando como modelo la Conjura de Catilina de Salustio-. Mientras que en otros lugares de esa misma obra ofrece un cuadro bien documentado de la situación y de los poderes italianos (Palencia 1970-1974: XXXII/6, 50-53; trad. vol.II, 61-64), dedica espacio a los conflictos entre Génova y Milán, al hilo de los cuales describe los intereses de Fernando de Nápoles en Sicilia y en la corona de Aragón (Palencia 1970-1974: XXXIII/1, 65; trad. vol. II, p.79), y se ocupa de las peripecias que abocaron a Lorenzo de Medici a pedir socorro al rey de Nápoles: noticias todas presentadas con una visión crítica de amplio alcance (Palencia 1970-1974: XXXV/7, 151; trad. vol. II, p. 177).

Al filo de los años ochenta la carrera política de Palencia se vería truncada por la pérdida del favor de la reina Isabel sin que sea dado conocer los motivos que llevaron a ese cambio de actitud. Sabemos solo lo que el propio autor relata en su obra historiográfica, esto es, que durante una sesión en las Cortes de Toledo, el domingo 6 de febrero de 1480, la reina lo relegó a un segundo plano contra su voluntad. Inició así un período de retiro en Sevilla que se prolongaría hasta su muerte, en 1492.

\section{EL CARÁCTER HUMANÍSTICO DE SU PRODUCCIÓN LITERARIA}

Tras este somero recorrido biográfico, convendrá resumir el status quaestionis sobre el mayor o menor influjo humanista perceptible en algunas obras de Palencia.

Comenzaré por sus dos tratados alegóricos en latín (los únicos escritos literarios que autotradujo) ${ }^{16}$, sobre los cuales permanece abierta la cuestión de si han de ser relegados a la tradición medieval o si denotan un espíritu humanista de raíz italiana. El primero de ellos es el titulado Bellum luporum cum canibus, dedicado a Alfonso de Olivares, maestresala del rey y compañero de residencia en el palacio arzobispal de Sevilla. La versión latina está perdida, pero existe constancia de que su redacción se llevó a cabo hacia 1456 (Durán Barceló 1995: II, 291). Posteriormente, en 1457, Palencia lo tradujo al castellano, con el título Batalla campal de los perros contra los lobos $^{17}$. La obrita iba dedicada a Alfonso de Herrera, otro familiar de Alfonso Fonseca I, «satisfaziendo a sus ruegos sobre el romançar», y en ella se describe una pelea

\footnotetext{
${ }^{15}$ El relato forma parte de la Cuarta década (Palencia ed. 1970-1974: XXXI, 10).

${ }^{16}$ Para las autotraducciones, un fenómeno no inhabitual a lo largo de la Edad Media, cf. Alvar (2010: 249); Cátedra (1991: 67-84).

${ }^{17}$ Así lo indica el propio Palencia: «Este tratado de los lobos y perros»-son sus propias palabras«fue compuesto en el año del Señor de mil i quatrocientos i çinquenta i siete años». La versión impresa se encuentra en Palencia (c. 1490), Batalla Campal de los lobos y los perros, Sevilla: Cuatro compañeros alemanes (Pablo de Colonia, Juan Pegnitzer, Magno Herbst, Tomás Glockner), y solo se conserva un ejemplar, Madrid, Biblioteca Real de Palacio, INC 172. Cf. Durán Barceló (1995: 291, III). Existen otras ediciones modernas de esta obra: Fabié (1876: i-viii; 1-105), una reproducción facsímil en López Serrano (1945: 255-302) y otra edición en Arancón (1980: 151-161).
} 
entre unos lobos y los perros guardianes del rebaño del pueblo. La alegoría pastoril, tan común en aquella centuria para la sátira político-moral, está repleta de referencias a Juan II, Don Álvaro de Luna, el Marqués de Santillana y la batalla de Olmito. Tate ha establecido un nexo entre la ideación de este relato y los contactos de Palencia con el círculo florentino y Bessarión, donde habría podido conocer a Marsuppini, o, al menos, leer su traducción de la Batrachomiomachia (Tate 1979: 29). Sin embargo la cuestión permanece abierta a la espera de un estudio más preciso.

La segunda obrita alegórica se ha conservado tanto en su versión latina, De perfectione militaris triumphi, como en la castellana, llevada a cabo en 1459 con el título de La Perfeçión del Triunfo ${ }^{18}$. El original latino iba dirigido al arzobispo de Toledo Alfonso Carrillo, mientras que la versión castellana estaba dedicaba a Fernando de Guzmán, comendador de la orden de Calatrava. En el prólogo a esta última Palencia se atenía a la oposición "fábula" vs "historia", inclinándose por la segunda, pero justificaba el recurso a la alegoría con la necesidad de usar algún tipo de disfraz para decir verdades incómodas que podían poner en riesgo la protección de los principales de su provincia (Palencia 1996: 131). Durán Barceló ha extendido a los dos opúsculos y a sus respectivas traducciones la tesis de Tate, concluyendo que «la mezcla de géneros y la diversidad de modelos revela la influencia de la literatura florentina producida en la década de 1440» (Palencia 1996: 18); más aún, sugiere como modelo, aunque sin ahondar en ello, las Intercoenales de Leon Battista Alberti. Como vemos, existe un campo de búsqueda sumamente interesante sobre fuentes y modelos italianos de Palencia en una vertiente poco estudiada hasta ahora de su obra: la literatura de ficción, que demasiado apresuradamente se ha tendido a desligar de sus trabajos más reconocidos, al igual que solo recientemente las Intercoenales de Alberti han sido rescatadas por la crítica (Alberti 2010).

Al segundo período, más focalizado en la producción historiográfica (14601480) pertenecen varias epístolas, una obra lexicográfica y la redacción de las tres Décadas sobre la historia contemporánea. Desde la óptica humanista, destaca especialmente el De sinonymis elegantibus, también conocida como Opus Synonymorum $^{19}$ (176 hojas sin foliar). Esta obra -falta aún una edición moderna- está dividida en tres libros: el primero trata del nombre, el pronombre y el participio, el segundo del verbo, y el tercero de las otras partes de la oración. Su dedicatoria al

${ }^{18}$ Durán Barceló (1995: IV, 292) censa solo dos manuscritos (Monasterio de San Lorenzo del Escorial, S.III.14, f. 58-118 y Madrid, BNE, ms. 10.076). Las ediciones modernas son Fabié (1876: I167) (la numeración es independiente y recomienza en cada obra, en primer lugar sitúa la Batalla y a continuación la Perfeçión), Palencia (1959: 345-392), la más actual y completa, Palencia (1996) y Real Torres (1995) (non uidi).

${ }^{19}$ El único manuscrito conservado es el autógrafo: Madrid, Biblioteca del Marqués de Valdecillas (antes Biblioteca del Noviciado), MS 128, fechado en 1472. La versión impresa: Palencia (1491), De sinonymis, Sevilla: Meynardo Ungut y Stanislao Polono, de la que se conservan ocho ejemplares, Cf. Durán Barceló (1995: X, 293). Existe la versión digital en la Biblioteca Cervantes Virtual (http://www.cervantesvirtual.com). 
obispo Alfonso de Fonseca I lleva como fecha 1472, lo cual sitúa su gestación en los años posteriores al regreso de la curia romana. Sin duda lecturas y estímulos italianos se hallan detrás de ella.

A este propósito, Sabbadini (1920: 29-30), en su clásico estudio sobre el método de los humanistas, dedica un apartado a la lexicografía y recuerda el entusiasmo de esta época por los vocabularios y por las colecciones de sinónimos (terra-humus), de diferencias (entre timor - metus), de homónimos (nepos: nieto y disipador), trayendo a colación algunas obras como las de Stefano Fieschi, compuesta hacia 1436 (Synonyma verborum, Synonyma sententiarum). Evidentemente, aunque con una estructura distinta, debemos añadir las Elegantiae linguae latinae de Lorenzo Valla, cuyo título presenta un claro parecido con el de Palencia ${ }^{20}$. Respecto a este último punto, conviene reproducir el incipit del prólogo palenciano. En cualquier caso, las dudas quedan zanjadas por el prólogo que el propio Palencia antepuso a la obra, y cuyo exordio reproduzco:

Diu et ualde admiratus in curiam eruditissimorum patrum: qui priscis temporibus floruerunt: quod sinonymorum elegantias uel lente uel modice attingerint: cura non mediocri agitabar: hoc ne ipsum opus aggrederer: ego paruulus latitantis sectator. qui castas uocabulorum significationes potuis adamauerim: quam eas enucleate proferre sim compos: an cederem tante rei (Palencia 1491: f.1r).

Como vemos, nuestro autor expresa aquí su admiración por los hombres sumamente eruditos de la curia romana que habían estudiado las elegancias de los sinónimos, y en cuya estela pretendía situarse desde su modesta posición de diletante. Otro hilo, pues, nos conduce a fuentes y modelos humanistas italianos, en este caso, expresamente reconocidos por el autor.

La tercera fase de la producción de Palencia (1480-1492) coincide grosso modo con su retiro en Sevilla y representa el momento más productivo de su carrera literaria. Cabe concordar a este respecto con Tate y Lawrence cuando destacan de esta época una acentuación de su vertiente más propiamente humanística: «son notables su abandono de la alegoría y su fuerte preferencia por las manifestaciones más eruditas del humanismo profesional - la gramática, la retórica y la traducción» (Palencia ed. 1998: LI).

Así, a lo largo de estos años, encontramos el Compendiolum de oblitteratis mutatisque nominibus prouinciarum fluminumque Hispaniae ${ }^{21}$, compuesto en 1482 bajo forma epistolar y dirigido a un «Petro Pontano archipresulis Toletani», del que poco sabemos y que Tate identifica con Pedro de Ponte o Piero Pontano, secretario

\footnotetext{
${ }^{20}$ Regoliosi (1993, 2010); una edición crítica con traducción castellana en Valla (1999).

${ }^{21}$ La obra se contiene únicamente en el manuscrito: Abadía de Montserrat, ms. 882, ff. 16-27v, con fecha de VII. Kal. Sextilis (=26 de agosto) 1482; fue editada por Mundó y Tate (1975); ulterior bibliografía en Durán Barceló (1995: 294, XII).
} 
por algún tiempo de Alfonso Carrillo, arzobispo de Toledo (cf. Mundó y Tate 1975: 255; Gómez Moreno 1994: 306). A instancias de este italiano, Palencia redactó un breve tratado sobre los nombres geográficos de las ciudades, pueblos y ríos citados por los geógrafos y después caídos en desuso, modificados por la invasión de los árabes o por las ocupaciones hispánicas. Se trataba, en definitiva, de identificar la correspondencia entre los topónimos transmitidos por los autores clásicos y sus equivalentes modernos ${ }^{22}$. Por lo que se refiere a las fuentes del Compendiolum, Tate y Mundó ya señalaron la riqueza y variedad de las mismas: Pomponio Mela, Plinio el Viejo, Estrabón, Livio, Justino, Eutropio, etc (Mundó y Tate 1975: 260). Era pues este opúsculo un claro tributo a su devoción por la historiografía clásica.

Hacia 1488 Palencia finalizó la que sería su gran obra lexicográfica, el Universal vocabulario en latin e en romançe collegido por el cronista Alfonso de Palencia (349 fols.), impreso en Sevilla por Pablo de Colonia en $1490^{23}$. La obra se estructura en dos columnas paralelas, una recoge solo los términos en latín, acompañados de su definición, y la otra la traducción al castellano tanto del término como de la definición, conformando así un instrumento muy útil para el estudio del latín, habida cuenta de los pocos recursos que se tenían en la época ${ }^{24}$. Palencia dedicó su magna empresa a la reina Isabel I y elaboró un interesante prólogo, que contiene «la mençión del trabajo», elenco de los trabajos realizados por el autor y los que proyectaba todavía llevar a cabo.

${ }^{22}$ Palencia define así su objetivo: «breue compendiolum, quo ciuitatum, oppidorum atque fluminum nomina a geographis commendatioribus olim indicta, postmodum autem ob maurorum inuasionem atque occupationem Hispaniarum uel oblitterata uel peruersa innotescant tibi huiusce scrutinii cupidissimo» (Mundó y Tate 1975: 264).

${ }^{23}$ Del Universal Vocabulario conservamos dos manuscritos: León, Colegiata de San Isidoro, ms. LII, contiene el primer volumen, correspondiente a las letras A-N; mientras que Monasterio de San Lorenzo del Escorial, ms. f. II 11, corresponde al segundo tomo y abarca las letras O-Z, fechado el 11 de febrero de 1488; en este último aparece un colofón fechado: 12 de febrero de 1487. La versión impresa tuvo lugar años después de su conclusión: Palencia (1490), Universal Vocabulario en Latín y en Romance, 2 vols., Sevilla: Pablo de Colonia, Juan Pegnitzer, Magno Herbt y Tomás Glockner. (Existe un ejemplar en línea: http://www.cervantesvirtual.com). Otra bibliografía y ejemplares incunables, cf. Durán Barceló (1995: 294, núm. XI). A finales de los años cincuenta se elaboró un registro de las voces internas castellanas del Universal Vocabulario en Palencia (1957); una edición facsímil en: Palencia (1967); y además en ADMYTE (1992), en CD-ROM. Como peculiaridad extraordinaria, poco común, de esta obra se conserva el original de imprenta, el ms. f-II-11 de la Biblioteca del Escorial, y el impreso correspondiente del año 1490 (Gómez Moreno 2010: 19-42).

${ }^{24}$ Algunos trabajos útiles sobre Palencia y el panorama general lexicográfico español en sus inicios son Freifrau von Gemmingen (2003: esp. 164-167), Alemany Ferrer (1981: 119-132) y Niederehe (1986: 39-54), que demuestra que Papias es su fuente principal a partir de un cotejo de las dos obras. Este autor persiste en la idea que «el diccionario de Fernández de Palencia, aunque declara seguir la pauta de los humanistas, no es otra cosa que una traducción fiel de un diccionario monolingüe latino del siglo XI, el del italiano Papias, y por consiguiente no se puede considerar como una obra renacentista propiamente tal» (Niederehe 1987: 160). Cf. también Medina Guerra (1991: 45-60). 
El Universal Vocabulario, pese a su enorme valor lexicográfico, se vio enseguida eclipsado por el Diccionario latino-español (1492) y, posteriormente, el Vocabulario español-latino de Elio Antonio de Nebrija, como prueba la ausencia de reediciones del Universal Vocabulario, frente al éxito clamoroso de los dos diccionarios del lebrisense. Sin lugar a dudas, la obra palentina presenta algunas novedades reseñables que merecerían ulteriores estudios pero comúnmente su estructura básica se considera deudora esencialmente de fuentes medievales de tradición isidoriana como el Elementarium Doctrinae Rudimentum de Papias (s. XI), texto archiconocido que circulaba en múltiples versiones manuscritas e impresas (Niederehe 1986: 42-52). Ciertamente, el Diccionario latino-español de Nebrija, además de doblar el número de voces -el Vocabulario palentino contenía una cantidad nada desdeñable de 14.000 voces, mientras que el de Nebrija tenía 28.000 - reviste mayor originalidad respecto a la tradición precedente, como ha señalado Medina Guerra (1991: 60). Se percibe, en definitiva, una diferencia de óptica que distingue sus obras, una más arraigada en la tradición, la otra fuertemente innovadora, pero quedan todavía por realizar estudios más profundos sobre esta original iniciativa lexicográfica palentina.

Por último, y como ya he tratado de aclarar en otra sede (Allés Torrent 2008: 112-120), sus traducciones de Flavio Josefo y de Plutarco, realizadas a través del latín, han de ser insertadas en el marco de su vocación humanística, tanto más en el caso de este último autor.

Cabe recordar, ante todo, que la traducción de las Vidas de Plutarco fue impresa el 2 de julio de 1491 en Sevilla, en 2 volúmenes, por los «Cuatro compañeros alemanes», Pablo de Colonia, Juan Pegnitzer de Nuremberga, Magno Herbs de Fils y Thomas Glockner ${ }^{25}$. Palencia tenía entonces una edad muy avanzada, y como explicaba en el prólogo, temía que la muerte lo sorprendiera sin ver concluida su obra. No cabe duda de que el autor volvió a traducir a partir de las versiones latinas de las Vidas plutarqueas realizadas por destacados humanistas italianos y reunidas por primera vez por Giovannantonio Campano bajo el título de Parallelae, sive Vitae illustrium virorum (Roma: Ulrich Han, c. 1470), y cuyo segundo volumen contenía también otras vidas compuestas a imitación de Plutarco por algunos de ellos (Bruni, Acciaiuoli y Guarino Veronese). Concretamente nuestro autor tomó como base la segunda edición veneciana (Venecia: Nicolas Jenson, 1478).

No podemos no retrotraer el interés de Palencia por Plutarco a la época de su formación en Florencia, justo cuando las miradas de los humanistas italianos se estaban volviendo hacia el historiador griego, ni es posible olvidar que Palencia fue pionero en trasladar a la lengua castellana la magna obra biográfica de Plutarco, que, como afirmaba en el prólogo, quiso ofrecer a la nobleza castellana con un intento marcadamente humanista: el de ofrecer modelos antiguos de conducta.

\footnotetext{
${ }^{25}$ Plutarco (1491), [Parallelae sive Vitae illustrium virorum], trad. Alfonso de Palencia, Sevilla; solo reimpresas en el siglo XVIII por Francisco Cerdá y Rico (Plutarco 1792-1793).
} 
Pero la estructura compuesta de las Parallelae, ideada por Campano y reimpresa con pocas modificaciones por Jenson, añade a la lista de traducciones palentinas obritas latinas pseudo-plutarqueas de no poco interés: la Vida de Ático de Cornelio Nepote y el Breviario de historia romana de Rufo (ambas escolásticas), tres obras helénicas: el Evágoras de Isócrates, una Vida de Homero atribuida falsamente a Plutarco ${ }^{26}$ y la biografía de Agesilao debida a Jenofonte. Cito por último las que revisten mayor importancia desde una perspectiva italianista: la Vita Aristotelis y el Cicero Novus de Leonardo Bruni, la Vita Aristotelis de Guarino, las tres biografías de Donato Acciaiuoli: las Vitae Hannibalis et Scipionis y Vita Caroli Magni ${ }^{27}$. Obras todas escritas en un latín humanista, acuñado por modernos émulos de Cicerón, que nuestro autor se esforzó por adaptar a la lengua castellana obteniendo una solución híbrida pero innovadora en ciertos aspectos (Allés Torrent 2011: 239-329).

El otro gran hito de Palencia como traductor se sitúa también a finales de marzo de 1492 cuando salió de la imprenta sevillana de Meynardo Ungut y Stanislao Polono la traducción de la Guerra de los judios con los romanos y los dos libros del Contra Apión gramático de Flavio Josefo ${ }^{28}$. El colofón de la edición está fechado en Sevilla por Ungut y Polono el 27 de marzo 1492, pero el explicit anuncia que fue «traduzida en romançe castellano por el cronista Alfonso de Palencia en el año de nuestra salud de M.CCCC.XCI.años». Posteriormente, y sin el Contra Apión gramático, fue reimpresa en 1532 y 1536 por Juan Cromberger en Sevilla ${ }^{29}$.

La dedicatoria a la reina Isabel I elogiaba sus recientes victorias sobre los moros, que aquel mismo año culminaban con su expulsión de Granada, y en ella el «humil cronista» describía así la finalidad de su trabajo emprendido «en mi extrema vejez continuar el estilo de bien servir a Vuestra Alteza dentro de los umbrales de mi pobre morada, quando ya me viedan la edad y los acidentes della el exercicio que muchas vezes y en tiempo que era menester pude emplear en principales negocios tocantes a vuestra real corona, segun soy cierto que vuestra excellentissima gratitud

${ }^{26}$ Un estado de la cuestión sobre la traducción de las vidas de Homero realizadas por Pellegrino degli Agli se encuentra en Allés Torrent (en prensa).

${ }^{27}$ Sobre la traducción de Palencia de la Vita Caroli Magni de Acciaiuoli, véase Allés Torrent (2010: 61-74).

${ }^{28}$ Flavio Josefo (1492), Guerras de los judios con los romanos. Contra Apión Gramático, Sevilla: Meynardo Ungut. En 1532 y 1536 se reimprimió en Sevilla en los talleres de Juan Cromberger, cf. Durán Barceló (1995: 299-300, XIX y XX). En estas ediciones posteriores (1532 y 1536) se modificó la traducción palentina a partir de la de Erasmo; en este sentido, sería muy interesante para la historia de la lengua castellana el análisis de los pasajes modificados para determinar qué aspectos lingüísticos eran percibidos como arcaicos a los oídos de los lectores de 30 años después.

${ }^{29}$ Para llevar a cabo la traducción de Josefo, Palencia -según sus propias palabras- se basó en la versión latina de Rufino di Aquileia («Prólogo del intérprete», Josefo 1532: f. 2r). Más concretamente, la obra a la que se remontaba Palencia era: Flavius Josephus (1480), De antiquitate Judaica. De bello Judaico, Verona: Petrus Maufer de Maliferis, aunque ya hubiera sido impresa con anterioridad (por ejemplo, en [Augsburg]: Johann Schüssler, 28 junio 1470; 23 agosto 1470), cf. Durán Barceló (1993:29, n. 9). 
tiene dello memoria» ${ }^{30}$. La traducción se reeditó varias veces y de su difusión da prueba además la presencia del Josefo en las bibliotecas de algunos nobles, como Pedro Fernández de Córdoba, Juan de Guzmán y Fadrique Enríquez de Ribera, marqués de Tarifa (Palencia ed. 1998: LIV).

\section{BERNARDO BEMBO Y PAOLO MARSI EN SEVILLA}

Otro personaje italiano de cierto relieve ha de sumarse a los contactos de Palencia: Paolo Marsi (o Marsio), desembarcado en Sevilla junto con Bernardo Bembo por cuestiones diplomáticas ${ }^{31}$. El episodio, descuidado por los biógrafos de Palencia, merece que me detenga en él con alguna extensión. Nacido en Pescina, Abruzzo, en 1440, Marsi se trasladó a Roma a la edad de diecisiete años, donde frecuentó las clases de Pomponio Leto con el que mantuvo en lo sucesivo estrechos lazos de amistad (Zabughin 1909-1912: 101s. y 170s). Hacia 1463 abandonó Roma, para trasladarse unos años a Perugia, donde impartió clases en el Studio entre 1466 y 1467; en 1468 se instaló en Venecia y allí entró al servicio de Bernardo Bembo, padre del famoso Pietro, a quien acompañó en diversas embajadas (cf. Giannetto (1985: 27, 79, 116-118, 273, 341-343) y, además, Ventura y Pecoraro 1966: 103109). De vuelta a tierras venecianas, siguió a Niccolò Canal en la expedición contra los turcos en Negroponte, cuyos hechos le inspiraron una Lamentatio (1470). Posteriormente, ejerció como tutor del hijo de Marco Cornaro, hasta que hacia 1480 decidió volver a Roma para enseñar en el Studio y donde fue miembro de la Academia Pomponiana. Allí murió en 1484.

En agosto de 1468, Bernardo Bembo recibió uno de sus primeros encargos por parte del senado veneciano como embajador ante el rey Enrique IV de Castilla, encargo que se prolongaría hasta febrero de 1469. En él llevó como acompañante a Paolo Marsi, que describió los avatares de la travesía desde Venecia hasta Sevilla en la Bembica peregrinatio o Bembice ${ }^{32}$, tal como el propio Marsi titula la obrita en el prólogo:

\footnotetext{
${ }^{30}$ Cito del ejemplar consultado: Josefo (1532), Barcelona, Biblioteca Nacional de Catalunya, Res. 4 fol., f. 2 r.

${ }^{31}$ Un estudio útil es el de Ventura y Pecoraro (1966: 103-109). La monografía más extensa continúa siendo Della Torre (1903: 163-164). Conviene no confundirlo con Pietro Marso (c.1441- 1511), también relacionado con Pomponio Leto y su Accademia (cf. Benedetti 2008: 6).

${ }^{32}$ La Bembice Peregrinae se conserva solo en tres manuscritos: Ferrara, Biblioteca comunale Ariostea, II.162, cc.166-200, una miscelánea preparada por Bernardo Bembo con composiciones dedicadas a él; Città del Vaticano, BAV, Reg. lat., 1385, cc. 1-38, al parecer un borrador, con correcciones e intervenciones de B. Bembo; Windsor, Eton College Library, Mss., 156, ff. 1r-35r (Inc. «P. Marrsi Pierii piscinatis Bembice peregrine et primo librum alloquitur suum...»), con notas marginales atribuidas a Bembo (este ha sido el único manuscrito consultado por el momento), cuya descripción se encuentra en Ker (1977). Cf. Fritsen (2000: 356-382); Kristeller (1997: 344).
} 
Qui tua parue liber nomina scire uelit Bembica de Bembo uolo quod peregrina uoceris

Quo simul errando, te peperisse liquet (Carmen 1, f.3r, lin.2-4).

Dedicada a Bernardo Bembo ${ }^{33}$, la Bembice describe el embarque en el mar Adriático, el paso por Siracusa, donde los habitantes les negaron el acceso a la ciudad ante el peligro de que su nave estuviera infectada por la peste; la navegación hasta Melita (Malta), Numidia, y la llegada finalmente a Cádiz y Sevilla. Una vez en la capital hispalense el relato describe las impresiones recibidas y el contacto mantenido con sus amigos venecianos y romanos; los cuales, en aquellos días, se hallaban encarcelados - como indica una nota manuscrita del propio Bernardo Bembo (Windsor, Eton College Library, Ms. 156 Eton, f. 22r)- por el papa Pablo II a causa de su pertenencia a la Academia pontaniana.

Las composiciones incluidas en el texto más interesantes para nuestro caso son las que se refieren a Sevilla. En ellas, Marsi -adoptando un tono bastante duro-cede ante la tópica barbarie de los hispani, y describe la lengua, las costumbres y sus duces, para concluir que todo lo perteneciente a Hesperia le hace anhelar a su amada Ausonia. Estos prejuicios, sin embargo, no impidieron a Marsi prendarse de una tal Beatriz, a la que dedica una composición erótica titulada De Beatrice Nimpha hispalica ${ }^{34}$, donde alaba su belleza conforme a las pautas de la descriptio puellae:

\author{
Illa comas nigrosque oculos, et lactea colla \\ Pectoraque ostendit candidiora niue. \\ Me solum alloquitur soli dat dulcia uerba \\ Que possent egros sollicitare senes. \\ Ex terra hec quamuis externam intelligo linguam \\ Nam didici hispana nunc ego uoce loqui (Carmen 18, f. 30r, lin.15).
}

En Sevilla Bembo y Marsi se alojaron en un palacio conocido popularmente, según indica el autor, con el nombre de «Enchassem» y cedido por un tal don Enrique al que Marsi dedica también una composición (núm. 15). No he hallado otras referencias al palacio con ese nombre, pero el illustrem Don Herricum bien podría ser Enrique de Guzmán, duque de Medina Sidonia, uno de los próceres más relevantes

\footnotetext{
${ }^{33}$ Estas son las palabras con las que Marsi ofrece su obra a Bembo: «Exiguum q(uam)uis etiam tibi Bembe uouetur / Quo duce, iam liquidas prora secabit aquas» (Windsor, Eton College Library, Mss., 156, f.4v).

${ }^{34}$ Bembo añadió también esta vez al margen del manuscrito de Eton la siguiente apreciación: «qua captus fu(er)at. filo» (f. 30r), seguramente para remarcar que en efecto Marsi se prendó perdidamente de la sevillana.
} 
de la ciudad y uno de los más idóneos para ofrecer hospitalidad a embajadores venecianos ${ }^{35}$.

La composición titulada Ad Academicos uenetias incolentes (ff.27r-29r) está formada por 70 dísticos y merece toda nuestra atención porque allí aparece la referencia al humanista palentino. En su íncipit, Marsi se dirige a sus compatriotas italianos de Venecia, «ausonii uiri», afirmando que se encuentra en la «ultima terra», habitada por «gens effera», donde todo es bárbaro, tanto la lengua como los gobernantes y las costumbres, y donde incluso se desprecia el latín. Solo un ciudadano citado en el verso 13, destaca entre estas tinieblas de ignorancia, un Alfonso digno del «ausonio eloquio»:

Vnus hic Alfonsus, que(m) sacra Palentia misit

Vrbs vetus (Carmen, f. 27r, vv.15-16)

Tras estas palabras, Marsi teje el elogio del amigo hispano recomendándolo a los interlocutores italianos: Nevi, Paulum Emilio y Cylleni, cuya identidad no es aclarada (vv. 35-36: «Sec vos o clari si me coluistis amici / Hunc colite, et latiis concelebrate modis»).

Sobre Marsi y su obrita existe un solo estudio publicado por Arnaldo della Torre en 1903. Allí se comentaban brevemente los versos en cuestión sin llegar a identificar al personaje aludido:

Ma, passato il primo momento d'ammirazione per i monumenti moreschi di Siviglia, il Marsi cominciò ad annoiarsi. In quella XIX poesia della Bembice, indirizzata ad Academicos Venetias incolentes, che abbiamo già citata, il poeta, detto ai suoi amici che egli si trova in Siviglia, la città posta sulle gelide acque del Guadalquivir, soggiunge che non se ne trova troppo contento: barbara è la lingua, e barbari i costumi: solo un certo Alfonso si distingue sui conterranei, perchè sa il latino, e «Canit Hispanos reges ab origine prima ». Egli lo stima, anzi, rivolgendosi ai suoi amici, dice: «vos, o clari, si me coluistis, amici / Hunc colite, et latiis concelebrate modis». (Della Torre 1903: 163)

Aquel «Vnus hic Alfonsus, qu(a)e sacra Palentia misit» no podía ser otro que nuestro Alfonso de Palencia, máxime si tenemos en cuenta otras referencias que

${ }^{35}$ De hecho Ventura y Pecoraro (1966: 104) ya señalaban la relación de Bernardo Bembo con el duque de Medina Sidonia, Enrique de Guzmán: «Il primo incarico di rilievo a noi noto è l'ambasceria al re Enrico IV di Castiglia, che lo occupò almeno nel biennio 1468-69, se in seguito ai suoi uffici Enrico di Guzmán, duca di Medina Sidonia, confermava il 3 dicembre 1468 in Siviglia i privilegi già concessi dal padre ai Veneziani». La misma noticia era retomada por Fritsen (2000: 359). En lo que concierne a la ubicación del palacio podría tratarse de la Plaza del Duque, posteriormente llamada Plaza del Duque de la Victoria. 
concuerdan perfectamente con el carácter y la obra del humanista castellano ${ }^{36}$. Marsi lo describe, en efecto, como un hombre docto, de conversación agradable, erudita y elegante, resaltando sobre todo su faceta de historiador:

\section{Historie cultor, qua nemo illustrior alter. Temporibus $n$ (ost)ris protulit auctor opus. Hic canit hispanos Reges ab origine prima Hesperidum [...]}

Aclara además que en sus obras «Alphonsus» no solo narró los sucesos de Hispania desde sus orígenes hasta los tiempos modernos, sino que también rememoró los hechos de los latinos, por lo que ambos pueblos merecen estarle agradecidos: «Debent Hispani proceres, debentque latini». Finalmente, Marsi parece aludir a la situación políticamente comprometida de Palencia, ya que le recomienda recurrir a sus amigos italianos en caso de ayuda (vv.32-38). Recordemos que Palencia al regreso de su segundo viaje a Italia, hacia 1465 , se había visto involucrado en el conflicto entre enriqueños y alfonsistas, con el consiguiente riesgo para su posición, y que en julio de 1468 había iniciado otro conflicto entre la futura reina Isabel y Juana la Beltraneja. Todo parece indicar que Marsi conoció a Palencia en esa coyuntura, cuando el cronista se refugió en Sevilla hasta el otoño del año siguiente, antes de volcarse en la causa isabelina.

De Marsi es posible, pues, extraer algunas conclusiones: ante todo, que Palencia residía ya en Sevilla entre agosto de 1468 y febrero de 1469; que su condición era por entonces precaria, como había dejado traslucir en algunas de sus epístolas (vv. 31-34: «Debent Hispani proceres, debentque latini. / Debet et Alfonso regia cura meo / Namq(ue) fere extinctum facit hic clarescere nomen / Atque die functos ire per ora virum»); en fin, que su patria era Palencia (v.15) y, sobre todo, que había compuesto efectivamente las Antigüedades, una obra que abrazaba la historia de Hispania («Hic canit hispanos Reges ab origine prima / Hesperidum»), y cuyo terminus ante quem queda así establecido ${ }^{37}$. Los ojos críticos de un italiano nos permiten además percibir una imagen más que respetable de Palencia que le confiere entre sus contemporáneos un nivel «europeo».

\footnotetext{
${ }^{36}$ Fritsen (2000: 371, n. 41) señalaba rápidamente en nota a pie de página que el tal Alfonso se trataba de nuestro Alfonso de Palencia: «Marsi clearly has in mind Alfonso de Palencia, author of De perfectione militaris triumphi, and the only Spaniard in the fiftheen century truly competent in Latin poetry prior to the strides made in Latin grammar by Antonio de Nebrija».

${ }^{37}$ Tate (1970: 127) puntualizaba en su artículo que la existencia de los Diez libros de las antigüedades de España era solo supuesta.
} 


\section{ALFONSO DE PALENCIA ¿AUTOR DE UN POEMA ANTIMALATES- TIANO PARA PÍO II?}

No podemos cerrar este recorrido por los contactos con la península italiana de nuestro palentino sin hacer una breve mención a la propuesta de Augusto Campana (1966: 189-218), según la cual Alfonso de Palencia sería el autor de un poema antimalatestiano dedicado a Pío II, Enea Silvio Piccolomini. El dato abre evidentemente un tema de sumo interés que desafortunadamente no ha tenido eco en los estudios hispánicos sobre Alfonso de Palencia y que requiere todavía hoy ulteriores investigaciones.

Así pues, en el ámbito de la literatura propagandística, despunta una antología conocida como Epaeneticorum ad Pium II Pont. Max., en 5 libros, presente solamente en dos manuscritos y presumiblemente compilados por o para el papa Piccolomini $^{38}$, en la cual se recogen composiciones de diversos autores entre los cuales Orazio Romano, Pietro Ransano, Bartolomeo Scala, Giacomo da Rieti, Pier Candido Decembrio, Francesco di Antonio Loschi o Francesco Patrizi (Avesani 1968: 1597). Hay, además, una serie de poemas anónimos y uno en particular llamó la atención de Campana.

Uno de los manuscritos conservados, custodiado en la Biblioteca Civica de Trieste, ofrecía el siguiente título en mayúsculas:

EPAENETICORUM AD PIUM SECUNDUM PONT. MAX. LIBER TERCIUS EXPLICIT, INCIPIT QUARTUS SIGISMUNDIANE VERO AD EUNDEM AL. HISPAN. LIBER PRIMUS.

Al título le seguía una composición de 292 hexámetros, metro habitual en los poemas heroicos, que narraba los orígenes infernales y malvados de Sigismundo Pandolfo Malatesta, quien desde octubre de 1460 mantenía una guerra abierta con el papa Pío II. Como si de un Ezzelino da Romano se tratara, y al más puro estilo de un Albertino Mussato, el poeta pormenorizaba los detalles del nacimiento demoníaco y las diversas perfidias perpetradas por Malatesta, haciendo especial hincapié en los delitos de lujuria; sus funestos crímenes no hacían más que empañar la paz del papado, de modo que el poeta se auguraba la pronta victoria de tan noble patriarca. Unos versos publicistas con una clara intención propagandista y destinados a granjearse el favor de a quien iban dedicados.

Del título citado salta a la vista la abreviatura del que fuera el autor de los versos: «Al. Hispan.», un autor hispano con pocas coordenadas, a excepción de las dos iniciales que preceden el gentilicio. A este propósito, Campana, sin ser concluyente, hacía la siguiente propuesta:

${ }^{38}$ Los manuscritos en cuestión son: Trieste, Biblioteca Civica, cod. Rosetti Piccol. II 25 (antes Rosetti XII), la composición se halla en los ff. 164r-170r; y el Città del Vaticano, BAV, Chigiano I VII 260, ff. 174r-179v. 
Ma chi è questo autore, il cui nome ci è presentato in forma abbreviata e piuttosto enigmatica «Al. Hispan.»? Trattandosi di uno spagnolo, è ovvio pensare in primo luogo a un Alfonso o a un Alvaro. Io non posso dire certamente di avere eseguito una ricerca esauriente, ma tra gli Alfonsi e Alvari del tempo che mi si sono presentati, uno solo ne ho trovato che rispondesse alla triplice esigenza di essere spagnolo, umanista e stato a quel tempo in Italia. Propongo dunque, sia pure con la cautela che il caso comporta, la candidatura di Alfonsus de Palencia o Palentinus (Campana 1966: 191).

La identificación con un «Alphonsus Hispanus» es perfectamente lógica, pero no tanto hacerlo sin más con nuestro Alfonso de Palencia, ya que este, en su versión latina, no firma nunca como «Hispanus», sino como «Palentinus».

Con todo, lo cierto es que el carmen, reproducido por el mismo Campana al final de su trabajo, tiene ecos y un tono barroco muy similar a la Epistola XI escrita en ocasión de la muerte del obispo de Ávila, la narración bucólica donde la muerte y las Furias se enfrentan dramáticamente a las Virtudes para llevarse al Tostado. Debe de todos modos realizarse un análisis lingüístico exhaustivo del texto y una comparación con su obra conocida.

En lo tocante a su datación, Campana, a raíz de la detección de algunas posibles fuentes, fecha la composición entre la primavera de 1462 y el verano de $1463^{39}$, un período algo complicado en el que Palencia se había visto envuelto en el conflicto de los Fonseca, retirado de la primera línea de la actividad diplomática y en vísperas del segundo viaje a Roma. Ahora bien, cabría dilucidar con qué motivos pretendía ganarse el favor de papa Pío II, si era a título personal para mejorar su situación presente o en representación de algún protector. Lo cierto es que, al conocer la muerte de Pío II y la llegada del nuevo papa veneciano, Palencia mostró un sincero pesar (Palencia ed. 1998: VII/3/4, 292).

Como he señalado, Palencia era un autor sumamente informado de las novedades italianas y las fuentes a las que accedía gracias a su condición de cronista debían de ser múltiples. Aún así, no menciona a Malatesta en los Gesta Hispaniensia y carecemos, por el momento, de algún otro dato a ese respecto; pero no podemos descartar que entre las noticias procedentes de Italia llegara a sus oídos la de la enemistad de Enea Silvio Piccolomini y Sigismondo Pandolfo Malatesta ${ }^{40}$ y decidiera utilizarla como motivo de una composición propagandística con algún fín que nos es todavía desconocido.

${ }^{39}$ Campana (1966: 194 y 199) apunta como fuente del poema la versión escrita que circulaba de «l'orazione accusatoria di Andrea Benzi pronunziata per commissione di Pio II nel corso del processo canonico contro Sigismondo, nel solenne concistoro pubblico del 16 gennaio 1461», así como a la bula Discipula ueritatis, un tipo de documentos que -recordémoslo- pasaban por sus manos y podía refrendar.

${ }^{40} \mathrm{Al}$ menos el nombre del Malatesta debía ser conocido en algunos círculos castellanos desde la traducción de Nuño de Guzmán realizada entre los años 1453 y 1458 de la Orazione a Gismondo Pandolfo de Malatesta de Giannozzo Manetti. 


\section{CONCLUSIONES}

Del cuadro aquí trazado, emergen varios puntos a tener en cuenta sobre la figura de Alfonso de Palencia. En primer lugar, su formación en Florencia y Roma, a lo largo de casi una década, lo encauzó hacia las nuevas corrientes que allí se habían gestado y lo unió en muchos aspectos al espíritu humanístico. Palencia non solo continuó manteniendo contacto con las amistades que dejó en Italia (Vespasiano da Bisticci, Jorge de Trebisonda, el cardenal Bessarión, etc), sino que demuestra, muy especialmente en su producción historiográfica, estar al corriente de la actualidad italiana del momento (como el caso de la conjura de los Pazzi). Asimismo, en sus aspiraciones literarias se traslucen algunas prácticas que lo acomunan con la producción italiana de esta época: no solo en su método historiográfico, o en la literatura de ficción, sino también en sus obras lexicográficas y gramaticales -donde hemos apuntado a las Elegantiae de Valla como fuente de inspiración para el De sinonymis palentino-, además, claramente, de sus traducciones de autores clásicos, como Plutarco y Josefo. Hemos, en fin, sacado a la luz dos importantes datos que ensanchan esta dimensión europea; por un lado, una composición dedicada al palentino escrita por un humanista de la talla de Paolo Marsi, durante una embajada a Sevilla junto a Bernardo Bembo; por el otro, la posible atribución de la composición de un poema antimalatestiano dirigida al papa Piccolomini, que presenta algunas semejanzas con otros opúsculos palentinos. En definitiva, cuestiones todas que avalan la imagen de un Palencia que, aunque involucrado en los conflictos de Castilla, no dejó de tener la mirada puesta hacia tierras italianas.

\section{REFERENCIAS BIBLIOGRÁFICAS}

ADMYTE (1992): Archivo Digital de Manuscritos y textos españoles, CD-ROM, Madrid, Micronet.

AlberTI, Leon Battista (ed. 2010): Opere latine, ed. de R. Cardini, Roma, Poligrafico dello Stato.

ALEMANY FERRER, Rafael (1981): «Un antecedente olvidado de Antonio de Nebrija: la obra lexicográfica de Alonso de Palencia», Item. Revista de Ciencias Humanas 5, pp. 119-132

ALLÉS TORRENT, Susanna (2008): «Alfonso de Palencia y la traducción de las Vidas de Plutarco (nuevos datos en torno al texto de partida)», $C F C(L) 28(2)$, pp. 99-124.

AllÉS TORRENT, Susanna (2010): «The Vita Caroli Magni of Donato Acciaiuoli, Translated by Alfonso de Palencia (1491)», en Humanism and Christian Letters in Early Modern Iberia (1480-1630), B. TAYLOR \& A. COROLEU (eds.), Newcastle, Cambridge Scholars Publishing, pp. 61-74. 
ALLÉS TORRENT, Susanna (2011): "Parallelae sive Vitae illustrium virorum" (Las vidas de Plutarco, Sevilla 1491). Estudio y edición crítica de la traducción de Alfonso de Palencia de las vidas compuestas por Donato Acciaiuoli, Leonardo Bruni y Guarino Veronese. Tesis doctoral dirigida por M. N. Muñiz Muñiz, Barcelona, Universitat de Barcelona. Departament de Filologia Romànica.

AllÉS TORRENT, Susanna (en prensa): «Le Vite di Omero tradotte da Pellegrino degli Agli», en J. Meirihnos, A. Musco (eds.), Coesistenza e cooperazione nel Medioevo. Actes du IVe Congrès européen d'études médiévales de la F.I.D.E.M (Palerme, 23-27 juin 2009).

AlVAR, Carlos (2010): Traducciones y traductores. Materiales para una historia de la traducción en Castilla durante la Edad Media, Alcalá de Henares, Centro de Estudios Cervantinos (Historia y Literatura 2).

AmMANNATi PicCOlOMini, Iacopo (ed. 1997): Lettere (1444-1479), ed. de P. Cherubini, 3 vols., Roma, Pubblicazioni degli Archivi di Stato (Fonti XXV).

ArANCón, Ana M. (1980): Antología de Humanistas Españoles, Madrid, Editora Nacional.

Avesani, Rino (1968): «Epaeneticorum ad Pium II Pont. Max. libri V», en D. Maffei (ed.), Enea Silvio Piccolomini, Papa Pio II. Atti del convegno per il quinto centenario della morte e altri scritti, Siena, Accademia degli Intronati, pp. 15-97.

BENEDETTI, Stefano (2008): s.v. «Marso, Pietro», DBI 71, pp. 5-10.

CAMMELli, Giuseppe (1941): I dotti bizantini e le origini dell'umanesimo. I. Manuele Crisoloras, II. Giovanni Argiropulo, III. Demetrio Calcondila, Firenze, Vallecchi.

CAMPANA, Augusto (1966): «Poema antimalatestiano di un umanista spagnolo per Pio II», Atti e Memorie. Atti del convegno storico piccoliminiano, Ser. 8, vol. IV, Fasc. II (1964-65), Ancona, Deputazione di storia patria per le Marche, pp. 189218.

CÁTEDRA, Pedro M. (1991): «Un aspecto de la difusión del escrito en la Edad Media: la autotraducción al romance», Atalaya 2, pp. 67-84.

COllantes DE TERÁN, Antonio (1977): Sevilla en la Edad Media: la ciudad y sus hombres, Sevilla, Sección de publicaciones del Excmo. Ayuntamiento.

DElla TorRe, A. (1902): Storia dell'Accademia Platonica di Firenze, Firenze, G. Carnesecchi.

Della TORRe, Arnaldo (1903): Paolo Marsi da Pescina: contributo alla storia dell'Accademia Pomponiana, Rocca S. Casciano, L. Capelli.

DURÁN BARCEló, Francisco J. (1995): «Bibliografía de Alfonso de Palencia», en Boletín Bibliográfico de la Asociación Hispánica de Literatura Medieval, fasc. 9, pp. 289-335.

DURÁN BARCELÓ, Francisco J. (1998): «La escritura humanística en los códices de Alfonso de Palencia», en J. MATAS J. CABAllero et al. (eds.), Actas del Con- 
greso Internacional sobre Humanismo y Renacimiento, León, Universidad de León, Secretariado de Publicaciones, vol. II, pp. 311-318.

EuBEL, Konrad (1910-1914): Hierarchia Catholica Medii Aeui siue Summorum Pontificum, S.R.E. Cardinalium, Ecclesiarum Antistitum series, 3 vols., Münster, Libraria Regensbergiana.

FABIÉ, Antonio M. (1876): Dos tratados de Alfonso de Palencia (Batalla campal de los perros y lobos. Tratado de la perfeción del triunfo militar), Madrid, A Durán (Libros de Antaño 5).

FREIFRAU VON GEMMINGEN, Barbara (2003): «Los inicios de la lexicografía española», en A.M. Medina Guerra (coord.), Lexicografía española, Barcelona, Ariel, pp. 151-174

FRITSEN, Angela M. V. (2000): «Testing auctoritas: the travels of Paolo Marsi, 1468-1469», International Journal of the classical tradition, VI, pp. 356-382

GIANNETTO, Nella (1985): Bernardo Bembo umanista e politico veneziano, Firenze, L.S. Olschki.

GÓMEZ MoReno, Ángel (1994): España y la Italia de los humanistas. Primeros ecos, Madrid, Gredos.

GÓMEZ MORENO, Ángel (2010): «El hispanismo medievalista del siglo XXI», en J. Ortega (ed.), Nuevos hispanismos interdisciplinarios y trasatlánticos, Madrid/ Frankfurt am Main/México, D.F., Iberoamericana/Vervuert/Bonilla Artigas, pp. $19-42$.

JoSEFO, Flavio (1480): De antiquitate Judaica. De bello Judaico, Verona, Petrus Maufer de Maliferis.

JOSEFO, Flavio (1492): Guerras de los judios con los romanos. Contra Apión gramático, trad. Alfonso de Palencia, Sevilla, Meynardo Ungut y Stanislao Polono.

JOSEFO, Flavio (1532): Los siete libros que el auténtico hystoriador Flavio Josepho escrivió de la guerra que tuvieron los judios con los romanos y la destruyción de Jerusalem hecha por Vespasiano y Tito, Sevilla, Juan Cromberger.

KER, Neil R. (1977): Medieval manuscripts in British Libraries. vol. II, Oxford, Clarendon Press.

KRISTELLER, Paul O. (1997): Iter Italicum. A cumulative index to volumes I-VI, vol. I, Leiden, Brill.

LÓPEZ SERRANO, Matilde (1945): «El incunable Batalla campal de los perros contra los lobos», Revista de Bibliografía Nacional 6, pp. 255-302.

Medina Guerra, Antonia M. (1991): «Modernidad del Universal Vocabulario de Alfonso Fernández de Palencia», E.L.U.A. Estudios en lingüistica 7, pp. 45-60.

Monfasani, John (1976): George of Trebizond. A Biography and Study of his Rhetoric and Logic, Leiden, E.J. Brill.

MuNDÓ, Anscari (1964): «Una lletra d'Alfons de Palència a Vespasià da Bisticci», en R. De Maio (ed.), Studi di bibliografia e di storia in onore di Tammaro de Marinis, Verona, Valdonega, vol. III, pp. 271-281. 
Mundó, Anscari; TATE, Robert B. (1975): «The Compendiolum of Alfonso de Palencia: a humanist treatise on the geography of the Iberian Peninsula», Journal of Medieval and Renaissance Studies 5, pp. 253-78.

NiEDEREHE, Hans-Joseph (1986): «Das 'Universal Vocabulario' des Alfonso Fernández de Palencia (1490) und seine Quelle», en H.J. Niederehe \& A. Quilis (eds.), The History of Linguistics in Spain, Amsterdam, Philadelphia, J. Benjamins, pp. 39-54.

NiEDEREHE, Hans-Joseph (1987): «La lexicografía española desde los principios hasta el año 1599», en H. Aarsleff \& L.G. Kelly y H.J. Niederehe (eds.), Papers in the History of Linguistics, Amsterdam/Philadelphia, J. Benjamins, pp. 157167.

Palencia, Alfonso de (1490): Universal Vocabulario en Latín y en Romance, 2 vols., Sevilla: Pablo de Colonia, Juan Pegnitzer, Magno Herbt y Tomás Glockner.

PALENCIA, Alfonso de (ca.1490): Batalla Campal de los lobos y los perros, Sevilla, Cuatro compañeros alemanes (Pablo de Colonia, Juan Pegnitzer, Magno Herbst, Tomás Glockner).

Palencia, Alfonso de (1491): De sinonymis, Sevilla, Meynardo Ungut y Stanislao Polono.

PALENCIA, Alfonso de (ed. 1957): Universal Vocabulario. Registro de voces españolas internas, ed. de J.M. Hill, Madrid, Real Academia Española.

PALENCIA, Alfonso de (ed. 1959): «Tratado de la perfección del triunfo militar», ed. de M. Penna, Prosistas Castellanos del siglo XV, Madrid, Atlas, pp. 345-392 (Biblioteca de Autores Españoles, 116).

PALENCIA, Alfonso de (ed. 1967) Universal Vocabulario en latín y en romance, ed. de S. Gili Gaya, Madrid, Asociación de Academias de la Lengua Española, 2 vols.

Palencia, Alfonso de (ed. 1970-1974): Cuarta Década, estudio, texto latino y traducción castellana, ed. de J. López de Toro, Madrid, Real Academia de la Historia, 2 vols.

PALENCiA, Alfonso de (ed. 1982): Epistolas latinas, ed. de R.B. Tate y R. Alemany Ferrer, Bellaterra, Universitat Autónoma de Barcelona.

Palencia, Alfonso de (ed. 1996): De Perfectione militaris triumphi. La perfección del triunfo, ediciones críticas y estudio de J. Durán Barceló, Salamanca, Universidad de Salamanca.

Palencia, Alfonso de (ed. 1998): Gesta Hispaniensia: ex annalibus suorum dierum collecta, ed. de J. Lawrance y R.B. Tate, Madrid, RAH, 2 vols.

PlUTARCO (ed. c.1470): [Parallelae sive Vitae illustrium virorum], Roma, Ulrich Han.

PluTARCO (ed. 1478): [Parallelae sive Vitae illustrium virorum], Venecia, Nicolas Jenson.

PlUTARCO (ed. 1491): [Parallelae sive Vitae illustrium virorum], trad. de Alfonso de Palencia, Sevilla, Cuatro compañeros alemanes. 
PlUTARCO (ed. 1792-1793): Vidas de los varones ilustres griegos y romanos escritas por Plutarco; y traducidas por Alfonso de Palencia, Madrid, Imprenta Real.

PONTARI, Paolo (2007): s.v. «Paolo Marsi», DBI, p. 70.

REAL TORRES, Carolina (1995): Alfonso de Palencia entre el Medievo y el Renacimiento: edición crítica de su obra inédita "De perfectione militaris triumphi" y su traducción al castellano (Tesis doctoral inédita), La Laguna, Universidad de La Laguna.

REgOLIOSI, Mariangela (1993): Nel cantiere del Valla: elaborazione e montaggio delle 'Elegantie', Roma, Bulzoni.

REgOlIOSI, Mariangela (ed.) (2010): Lorenzo Valla e l'umanesimo toscano: Traversari, Bruni, Marsuppini. Atti del convegno del Comitato nazionale VI centenario della nascita di Lorenzo Valla, Prato, 30 novembre 2007, Firenze, Polistampa.

SABBADINI, Remigio (1920): Il metodo degli umanisti, Firenze, Le Monnier.

TATE, Robert B. (1970): Ensayos sobre la historiografía peninsular del siglo XV, Madrid, Gredos (Biblioteca Románica Hispánica, Estudios y Ensayos, 145).

TATE, Robert B. (1979): «The Civic Humanism of Alfonso de Palencia», Renaissance and Modern Studies 23, pp. 5-44.

TATE, Robert B. (1993): "Alfonso de Palencia: An interim biography», en A. Deyermond \& J. Lawrance (ed.), Letters and Society in fifteenth-century Spain. Studies presented to P.E. Russell on his eightieth birthday, [Oxford], The Dolphin Book, pp. 175-191.

VALla, Lorenzo (ed. 1999): De linguae latinae elegantia: ad Ioannem Tortellium Aretinum per me M. Nicolaum Ienson Venetiis opus feliciter impressum est. M.CCCC.LXXI, ed. y trad de S. López Moreda, Cáceres, Universidad de Extremadura, 2 vols.

Ventura, Angelo; PeCoraro, Marco (1966): s.v. «Bernando Bembo» en DBI 8, pp. 103-109.

ZABUGHIN, Vladimir (1909-1912): Giulio Pomponio Leto: saggio critico, Ro$\mathrm{ma} /$ Grottaferrata, La Vita letteraria/Tip. italo-orientale S. Nilo. 